\title{
A Boost Circuit Design of High-Precision Voltage Stabilized Power Supply
}

\author{
Hengxu Ma, Jiehao Chen, Jinge Zhou \\ School of Nuclear Technology \& Automation Engineering, Chengdu University of Technology, Chengdu, China \\ Email:17844649567@163.com
}

How to cite this paper: Ma, H.X., Chen, J.H. and Zhou, J.G. (2020) A Boost Circuit Design of High-Precision Voltage Stabilized Power Supply. Open Access Library Journal, 7: e6624.

https://doi.org/10.4236/oalib.1106624

Received: July 17, 2020

Accepted: August 22, 2020

Published: August 25, 2020

Copyright $\odot 2020$ by author(s) and Open Access Library Inc.

This work is licensed under the Creative Commons Attribution International License (CC BY 4.0).

http://creativecommons.org/licenses/by/4.0/

(c) (i) Open Access

\begin{abstract}
This paper presents a high-precision stabilized power supply boost circuit design. First, the MC34063ADG chip was selected to convert the voltage to $+15 \mathrm{~V}$ to meet the input voltage requirements of the voltage regulator chip afterwards. Then, the voltage regulator chip LM7812 suitable for circuit use was selected, which can use fewer external components to form a boost conversion circuit. Using Multisim software to simulate the circuit and system performance, analyze the circuit faults, calculate the circuit parameters, and optimize the circuit design for the problems during the simulation. Multisim simulation results show that the output voltage ripple of the circuit is less than $5 \mathrm{mV}$, the power supply regulation rate reaches $1.0 \%$, and the load regulation rate is 0 .
\end{abstract}

\section{Subject Areas}

Nuclear Technology and Nuclear Instruments

\section{Keywords}

High Precision Power Supply, MC34063ADG Chip

\section{Introduction}

With the continuous attention of society on environmental radiation, the development of nuclear instruments has entered a new era, and the corresponding power supply system is developing rapidly. This article focuses on the research of the power supply system supporting nuclear instruments, designing a regulated power supply that can achieve boost conversion and higher accuracy. It uses a simpler circuit structure and chip. It is suitable for nuclear instruments and other precision instruments and requires a regulated battery. Powered portable electronic products. 
The power supply module requires an input voltage of $7.4 \mathrm{~V}$ and an output voltage of $+12 \mathrm{~V}(1000 \mathrm{~mA})$. The power supply regulation rate is extremely low to ensure excellent output voltage stability. The load regulation rate is extremely low, which causes minimal impact on the power supply when the load is connected; temperature coefficient Extremely low, so that the power supply has little effect when the temperature changes greatly; the ripple is extremely small, which ensures the DC performance of the power supply is good.

\section{Overall Design}

\subsection{Selecting a Basic Design Ideas}

The design of a DC stabilized power supply that implements $7.4 \mathrm{~V}$ input and $+12 \mathrm{~V}$ output involves DC boost. Since the output of the MC34063 chip is not very stable [1], it cannot directly output $+12 \mathrm{~V}$ voltage through it. In order to achieve this requirement, the LM7812 chip was introduced in the design, as long as the voltage input requirements are met, $\mathrm{a}+12 \mathrm{~V}$ DC voltage can be stably output. That is, the MC34063ADG chip is only used as a transition to convert the original $+7.4 \mathrm{~V}$ voltage to $+15 \mathrm{~V}$ after boosting to provide the required input voltage for the LM7812 chip, thereby realizing the design of a $+12 \mathrm{~V} \mathrm{DC}$ regulated power supply. Figure 1 shows the basic ideas of stabilized power supply.

\subsection{Overall Design Block Diagram}

The design input voltage of the nuclear instrument power supply system is a 7.4 V DC battery voltage. After simple filtering, the DC power supply control circuit is provided with a PWM control signal to the boost converter circuit to control the on and off of the switch tube, which is used to adjust the DC voltage. Duty cycle, finally get a stable or adjustable DC output voltage. By sampling, comparing and amplifying the output voltage, the pulse width is adjusted, and finally the purpose of outputting a stable DC voltage is achieved by filtering. Figure 2 shows the overall design block diagram.

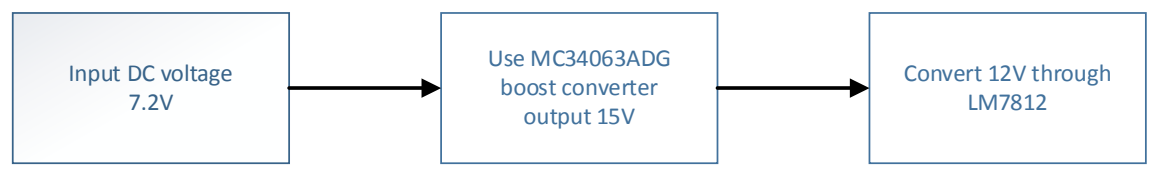

Figure 1. The basic idea of stabilized power supply.

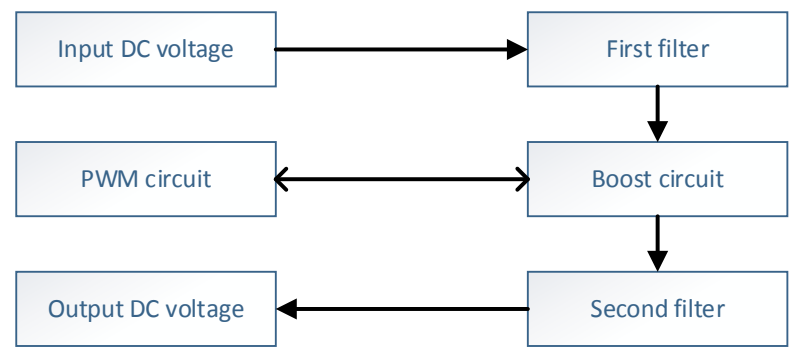

Figure 2. Overall design block diagram. 


\section{Unit Circuit}

\subsection{Schematic Design}

According to the above introduction about MC34063ADG chip and the basic principle design of the second section boost circuit, a $15 \mathrm{~V}$ boost converter circuit can be obtained [2], whose output voltage is adjustable from 1.25 to $40 \mathrm{~V}$. The output voltage sampling loop resistance is determined by $R 7$ and $R 6$. The output voltage can be changed by adjusting the resistance of $R 7$. The calculation formula of the output voltage is $V_{\text {out }}=1.25 \mathrm{~V}(1+R 7 / R 6)$, we take $R 7=11 \mathrm{~K} \Omega$, $R 6=1 \mathrm{~K} \Omega$ here, calculate The output is $15 \mathrm{~V}$, the LM7812 input terminal can work normally in the voltage range of $14.5 \sim 35 \mathrm{~V}, 15 \mathrm{~V}$ meets the requirements, so the LM7812 output terminal can output $+12 \mathrm{~V}$ [3].

From the above related discussion, the following circuit diagram of the $12 \mathrm{~V}$ boost power converter is obtained, as shown in Figure 3.

\subsection{Circuit Parameter Design Calculation}

1) Sampling loop resistance $R 7$ and $R 6: U_{O}$ (output voltage): Its voltage regulation value is determined by $R 7$ and $R 6$, and its calculation formula is:

$$
U_{O}=1.25\left(1+\frac{R 7}{R 6}\right)
$$

Sampling loop resistors $R 1$ and $R 2$ must shunt the output loop. In order to reduce power consumption, the shunt current value should be less than $0.001 \mathrm{~A}$ to not affect the performance of the system. therefore:

$$
R 7+R 6 \leq \frac{U_{O}}{0.001}=15000
$$

Calculated by the actual circuit:

$$
R_{7}=11 k, R_{6}=1 k
$$

2) $T_{o n}$ and $T_{\text {off }}$ values:

$$
\frac{T_{\text {on }}}{T_{\text {off }}}=\frac{(U o+U f-U i)}{U i-U s a t}=(15+1.2-7.4 / 7.4-1)=1.375
$$

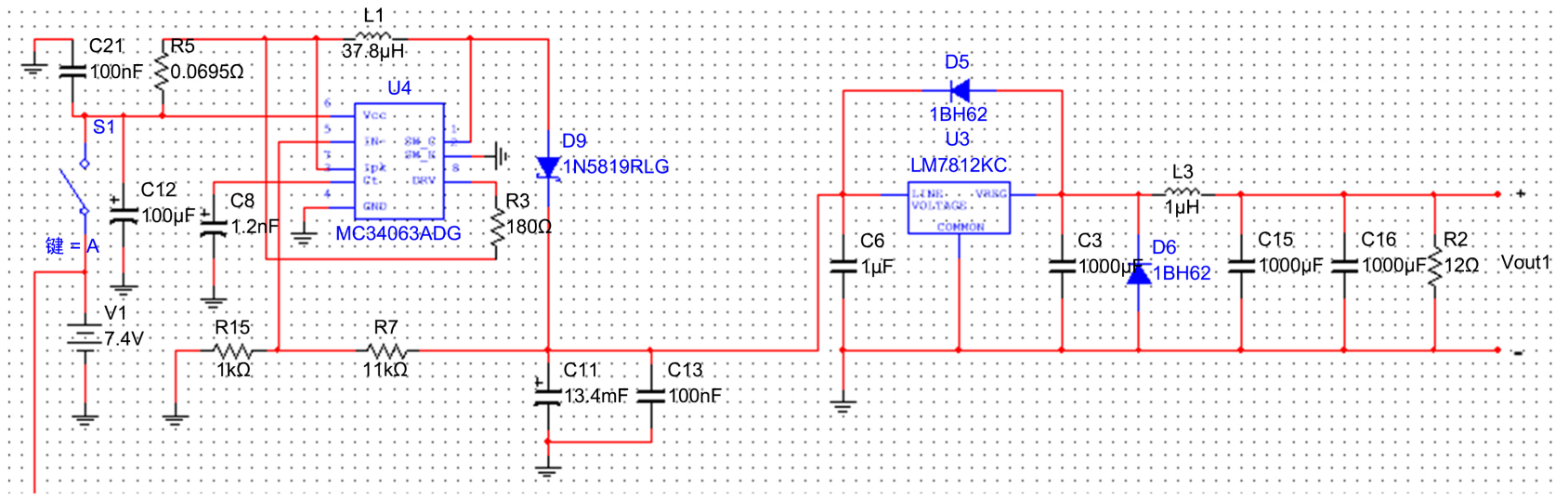

Figure 3. Boost converter circuit diagram. 
Among them: $U_{o}$ (output voltage), $U f$ is the forward voltage drop of the rectifier diode can take $1.2 \mathrm{~V}$, UI (input voltage), $U s$ is the saturation voltage drop of the switch tube can be taken $1.0 \mathrm{~V}, T_{\text {on }}$ is the switch tube conduction time, $T_{\text {off }}$ is Switch off time.

$$
T_{\text {on }}+T_{\text {off }}=\frac{1}{f \min }=5 \times 10^{-5} \mathrm{~s}
$$

3) The remaining relevant data, such as the current limiting resistor $R s c$, load peak current $I p k$, timing capacitor $C_{T}$, inductance $L$, filter capacitor $C_{o}$, etc., are calculated by the actual circuit:

$$
\begin{aligned}
& \text { Ipk }=4.75 \mathrm{~A} \\
& \text { Rse }=0.0695 \Omega \\
& C_{T}=1.2 n F \\
& L=37.8 u H \\
& C_{o}=13.4 m F
\end{aligned}
$$

\subsection{Summary}

According to the relevant performance of the MC34063ADG chip and the basic principles of the circuits in the second section, the principle diagram of the boost converter circuit is designed in conjunction with the LM7812. For the boost circuit, the parameters such as inductance, sampling loop resistance, filter capacitor $C_{o}$, timing capacitor $C_{T}$, switch-on time $T_{o n}$, switch-off time $T_{\text {off }}$ and other parameters need to be calculated and simulated according to the calculated parameter values.

\section{Software Emulation}

\subsection{Simulation Test Process}

Based on Multisim simulation, the input voltage is $7.4 \mathrm{~V}$, the timing capacitor is $1.2 \mathrm{nf}$, the filter capacitor is $13.4 \mathrm{mf}$, the current limiting resistor is $0.0695 \mathrm{ohms}$, the output voltage is measured with a multimeter 1 (XMM1), the output current is measured with a multimeter 2 (XMM2), and the oscilloscope 1 (XSC1) Measure the AC waveform generated at the input and output to analyze the ripple.

The simulation circuit is as follows (Figure 4).

Insert the voltage and current probe, the output voltage is $12.0 \mathrm{~V}$, the effect is obvious and relatively stable, the output current is $1 \mathrm{~A}$;

According to the output voltage and input voltage, calculate the boost power supply adjustment rate $\eta=|12 / 12-1| \times 100 \%=0$. (Because the simulation error is small and the voltage probe sensitivity is low);

Output voltage ripple is $170 \mathrm{uV}$, good stability;

Insert the voltage and current probe, the output voltage is $12.0 \mathrm{~V}$, the effect is obvious and relatively stable, the output current is $1.2 \mathrm{~mA}$; According to whether the two voltages of the load are connected, the boost load adjustment rate $\eta=|12 / 12-1| \times 100 \%=0$ is calculated. (Because the simulation error is small and the voltage probe sensitivity is low). 


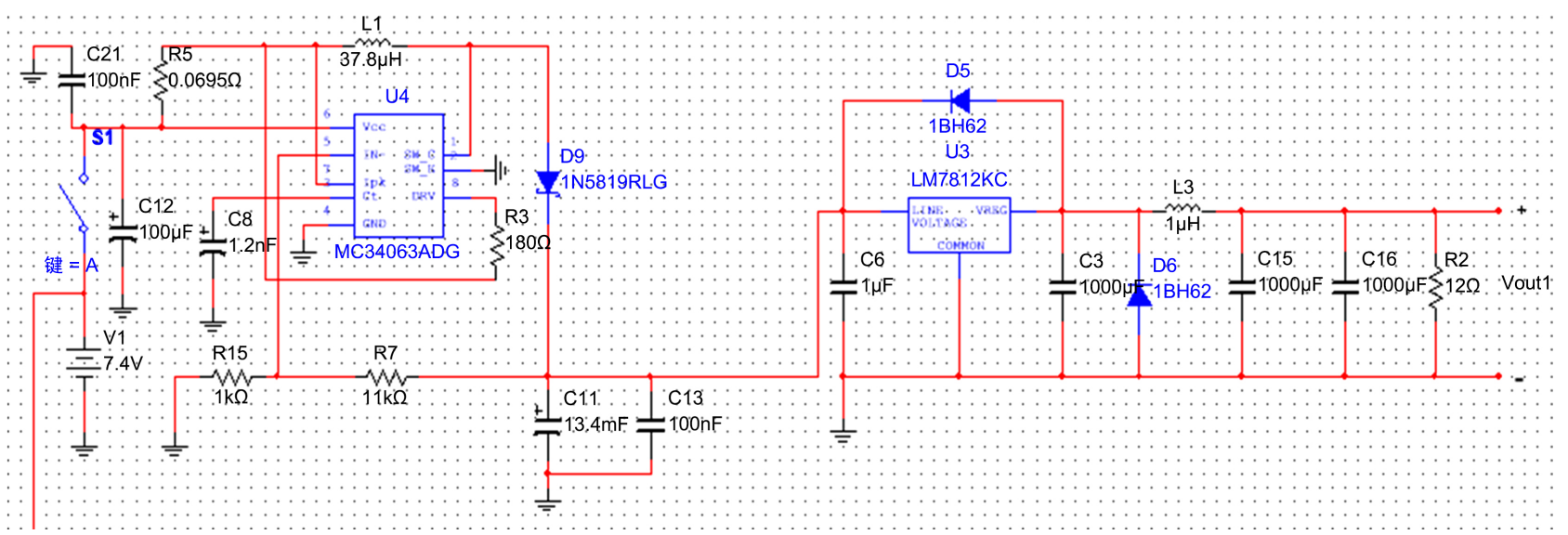

Figure 4. Simulation diagram of boost converter circuit.

\subsection{Summary}

In Multisim, the circuit is simulated in the experimental design schematic diagram, mainly to study the output voltage, output current, voltage regulation rate, load regulation rate, ripple and other parameters of each circuit under normal circuit operation. The simulation results show that the voltage and load adjustment rate of the circuit meet the requirements, of which the voltage adjustment rate is less than $1.0 \%$, the circuit output voltage is $12.0 \mathrm{~V}$, and the voltage adjustment rate is 0 , showing excellent high-precision voltage characteristics; measuring ripple, The output voltage ripple of the circuit is less than $5 \mathrm{mV}$, showing excellent voltage regulation characteristics.

\section{Acknowledgements}

Thanks to my classmate Jiehao Chen for supporting me in circuit design, and my brother Jinge Zhou for his great assistance in software simulation, so that I can design this circuit smoothly.

\section{Conflicts of Interest}

The authors declare no conflicts of interest regarding the publication of this paper.

\section{References}

[1] Guo, Z.Y. and Gao, F.Y. (2010) Design of Switching Power Supply Based on MC34063. Industrial Control Computer, 23, 100-101.

[2] Zhu, X. and Chen, J.B. (2014) Calculation Method of Switching Power Supply Circuit Parameters Based on MC34063. Daily Electrical Appliances, No. 3, 41-43.

[3] Mao, H., Wu, Z.L. and Shen, Q. (1999) System Analysis and Design of High-Precision Switching Power Supply. Power Electronics Technology, No. 2, 1-4. 